\title{
Review in Maintenance Strategies for Haemodialysis Machine in Healthcare Facilities
}

\author{
David Malombe Mutia ${ }^{1}$, Lawrence Mukhongo ${ }^{2}$, Peter Chemweno ${ }^{3}$ \\ ${ }^{1}$ Department of Medical Engineering, Technical University of Mombasa, Mombasa, Kenya \\ ${ }^{2}$ Department of Electrical Engineering, Technical University of Mombasa, Mombasa, Kenya \\ ${ }^{3}$ Department of Mechanical Engineering, Moi University, Eldoret, Kenya
}

Email address:

dmalombe@tum.ac.ke (D. M. Mutia),davimalombe@gmail.com (D. M. Mutia)

\section{To cite this article:}

David Malombe Mutia, Lawrence Mukhongo, Peter Chemweno. Review in Maintenance Strategies for Haemodialysis Machine in Healthcare Facilities. Industrial Engineering. Vol. 2, No. 1, 2018, pp. 34-41. doi: 10.11648/j.ie.20180201.15

Received: September 17, 2018; Accepted: September 29, 2018; Published: October 30, 2018

\begin{abstract}
Hemodialysis machines are critical medical equipment in healthcare facilities for renal replacement therapy in form of dialysis treatment on solving chronic kidney diseases in Sub Sahara Africa. It is a vital machine which acts as human kidney by incorporating electromechanical controlled extracorporeal blood paths that leverage pumps and semi permeable dialyzer membranes to filter the patient's blood. The biggest challenge to the biomedical engineers in most African hospitals is to maintain the manufacturer's safety and performance specification of the haemodialysis equipment. There is a need for effective maintenance strategy for haemodialysis medical equipment in order to maintain the manufacturer's set specification to meet clinical expectations and hence improve its reliability. The overall goal of the research paper is therefore to analyze the influence of different maintenance strategies and subsequently improve on the reliability of hemodialysis equipment in healthcare institutions in Kenya. The research will prioritize hemodialysis machine as critical medical equipment and use comprehensive secondary data to review and analyze the strategic maintenance applied in health institutions to optimize the best and cost effective strategic maintenance for the hemodialysis medical equipment. The ant colony optimization (ACO) algorithms may be less expert reliant and avoid uncertainty and ambiguity to determine the best strategic maintenance management to manage hemodialysis medical equipment in the hospitals. The results will provide an opportunity to technical engineers to develop a predictive and intelligent management system in the hospitals to minimize or remove the Mean Downtime (MDT) and Mean time to repair (MTTR) for a failed hemodialysis machines and improve the reliability of the hemodialysis machine.
\end{abstract}

Keywords: Health Facilities, Maintenance, Medical Equipment

\section{Introduction}

Hemodialysis machines are sensitive electromechanical systems used in the hospitals. Their sensitivity increases the adverse effects that may occur in case the machines fails their primary function as life support. The removal of renal fluid from a kidney patient is crucial to easy and employ comfort to the patient. This would be attained by a pressure gradient applied across the dialyzer which is in direct contact with blood $[1,2]$. To transport this fluid a sterile biologically inert tube is required.

In Kenya, rising incidence of kidney failures and disease is at high rate. One in every 10 Kenyans have kidney aliments. The situations have forced the National Insurance Health
Fund (NHIF) to review its policy to pay heavy claims for their clients. The dialysis machines in the kidney centers are forced to run for a long period to cope with high demands from the patients. The machines have become prone to failures of key components in the renal unit. The peristaltic pump is a positive displacement pump, which is commonly used in dialysis machines [3]. However, it has several disadvantages which affects its performance and efficiency in the dialysis machines. Due to extensive use and further wear of the tubing, calibration needs to be changed. When exchange is not experienced the tube may further leak and in some cases aqueous solution can be disadvantage as well. The deviance caused by peristaltic pumps during transfer volume can cause significant error at high pressure on medical fluid. The maximal differential pressure created by 
the peristaltic pups are lower comparison to gears and piston pumps. The flow rate is further affected by the varying differential pressure conditions [3]. The pressure in the medical fluid affects the safety, reliability and efficient operation of haemodialysis machine if not controlled. The salt solution used for cleaning the machine after dialysis may corrode the dialysis machines and further damage the dialysis system [4].

In addition, the lifespan of a part is reduced while maintenance and replacement costs increase. There is a need for effective maintenance for haemodialysis machine in order to attain manufacturer's specification and clinical requirement. Common factors related to haemodialysis machine maintenance include low blood pump and dialysate flow rates, under estimates of flow due to calibration errors and blood pump tubing collapse [5]. However, little existing literature do not provide answers for existing problems.

The study will review secondary data and attempt to link the best strategic maintenance available to haemodialysis machines in Kenyan Health Institutions.

\section{Medical Equipment Maintenance Management}

Hemodialysis Machines are medical processor based extracorporeal blood circulation equipment incorporating electromechanically controlled system that controls pumps and semi permeable dialyzer membranes to filter the patient's blood. They are therapeutic machines which acts as a life support and their failure may result to endangering the patient. Its sensitivity increases the adverse effects that may occur in case the machine fails its primary function as life support. Biomedical engineers are tasked to ensure dialysis machine attains the manufacturer's safety and performance specification when in use. During the treatment, the dialyzers system needs to transport this fluid through sterile and less contaminated pump tube. The peristaltic pump is commonly used in hemodialysis machines [3]. However, it has several disadvantages which affects its performance and efficiency in the hemodialysis machines. The peristaltic pumps are mainly involved on transfer of fluid volume which may depend on loaded tube. However, the transfer volume can differ by a range of $10 \%$ due to its production and may cause significant error especially at higher flow rates. It is necessary to transfer the fluid with utmost pressure and set volume [6]. Little literature have been proposed to control and stabilize the flow of the fluid in the hemodialysis machine.

Jzsef at al investigated an automatic control solution of peristaltic pumps for hemodialysis machines and implemented PID controller due to its ability to be a faster and accurate control at low flow rates [6]. An improved control mechanism with the use of adaptive fuzzy logic control and a neural system was proposed for hemodialysis model [7]. The reliability of hemodialysis machine to accomplish its main function of extracorporeal circulation and removal of waste products from the blood when the kidneys are in a state of renal failure can be improved by ensuring the dialysis equipment are available in a perfect state in the health facilities.

Suitable strategic maintenance ensures that the operation, quality and safety of hemodialysis machines are attained in order to support the provision of satisfactory healthcare. Hemodialysis as a critical medical devices in hospitals must operate and perform their respective tasks in a harmless, accurate, and reliable and further attain national and manufacturing standards. Patients had to sue the government of Kenya because of lack of modern hemodialysis machines in the local hospitals [8]. The dialysis machines in the existing hospital were not capable of handling the patients due to frequent breakdown. Hemodialysis machines are expected to work in long hours due to high demand of the service expected by the patients. This have been necessitated by the few numbers of the machines available to serve a large queue of kidney failure patients. Khalaf, [9] observed that the greatest problem for many developing countries notwithstanding the number of equipment supplied to the hospitals, $50 \%$ up to $75 \%$ of these equipment are defective. Frequent equipment failure and medical device malfunction are a sign that the maintenance and servicing program have failed.

Maintenance can be referred to the amalgamation of all terotechnology policy to a system with the intention to restore and retain it to a perfect state [10].

Equipment maintenance and repair is the most critical function which supports proper delivery of healthcare services. The WHO [11] observed that the biomedical engineers ought to optimize the best maintenance strategy to reduce the failure rate of medical equipment to improve the medical equipment reliability. The biomedical engineering sector has to ensure the safety of the equipment and the reduction of maintenance cost is paramount. Several challenges have seen hospitals and healthcare not experiencing excellence maintenance policy compared to other industrial organization [12].

Private and Public hospitals in Kenya have adopted preventive and corrective measures as the main maintenance policies for dialysis machines. However, preventive maintenance policy has several disadvantages which contribute to losses in the organizations. This includes and not limited to inadequacy in maintenance, costly time frame spent performing pointless preventive maintenance, needless and unwarranted maintenance procedures [13].

There is a need for effective maintenance strategy for hemodialysis machines as critical medical equipment in Kenya healthcare in order to maintain the medical equipment in manufacturers set specification and clinical requirement. Proper maintenance management policies can reduce overall medical equipment operation cost, decrease degradation and increase availability [14]. The Kenyan hospitals adopted the managed equipment services (MES) for a period of 10 years. A total of 98 hospitals which included county referral hospital and sub-county referral hospitals in Kenya. The MES program outsourced several equipment manufacturers 
to supply, install, train users, maintenance and replacement services for specialized medical equipment. The equipment included Theatre Equipment, Sterilization Equipment, ray and other Imaging Equipment for level 4 \& 5, Renal Dialysis Equipment for level 5 and 2 national hospitals and Intensive Care Unit (ICU) Equipment for 11 hospitals countrywide [15]. The MES program required the public private partnership to outsource the management of medical equipment services from procurement to replacement of aged/spoiled medical equipment as per recommendations of selected manufacturers. Despite the MES project being praised for promoting healthcare for sustainable development and innovative financing strategy, the hospitals are faced with the challenges as a result of outsourcing maintenance from external institutions which includes; long call response and repair time to downtime. This research paper attempts to link hemodialysis machines as an example of critical medical equipment with a suitable strategic maintenance policies. The maintenance strategy is responsible in maintaining the stability of dialysis system and become technically sound.

Maintenance management techniques have transformed from the simplest to the most complex process over the generations as shown in fig 1. The need to improve the maintenance strategy in the industrial sector has been necessitated by the improved awareness of personal safety in the industry, complex manufacturing processes, products, the need to improve profit in the business, quality of products and the impact of maintenance on the environment [16]. During the first generation maintenance period, industries were not automated and most equipment were simple and easy to repair. The maintenance technique during this era included; corrective maintenance or reactive breakdown service (fix it when it broke) and basic and routine maintenance.

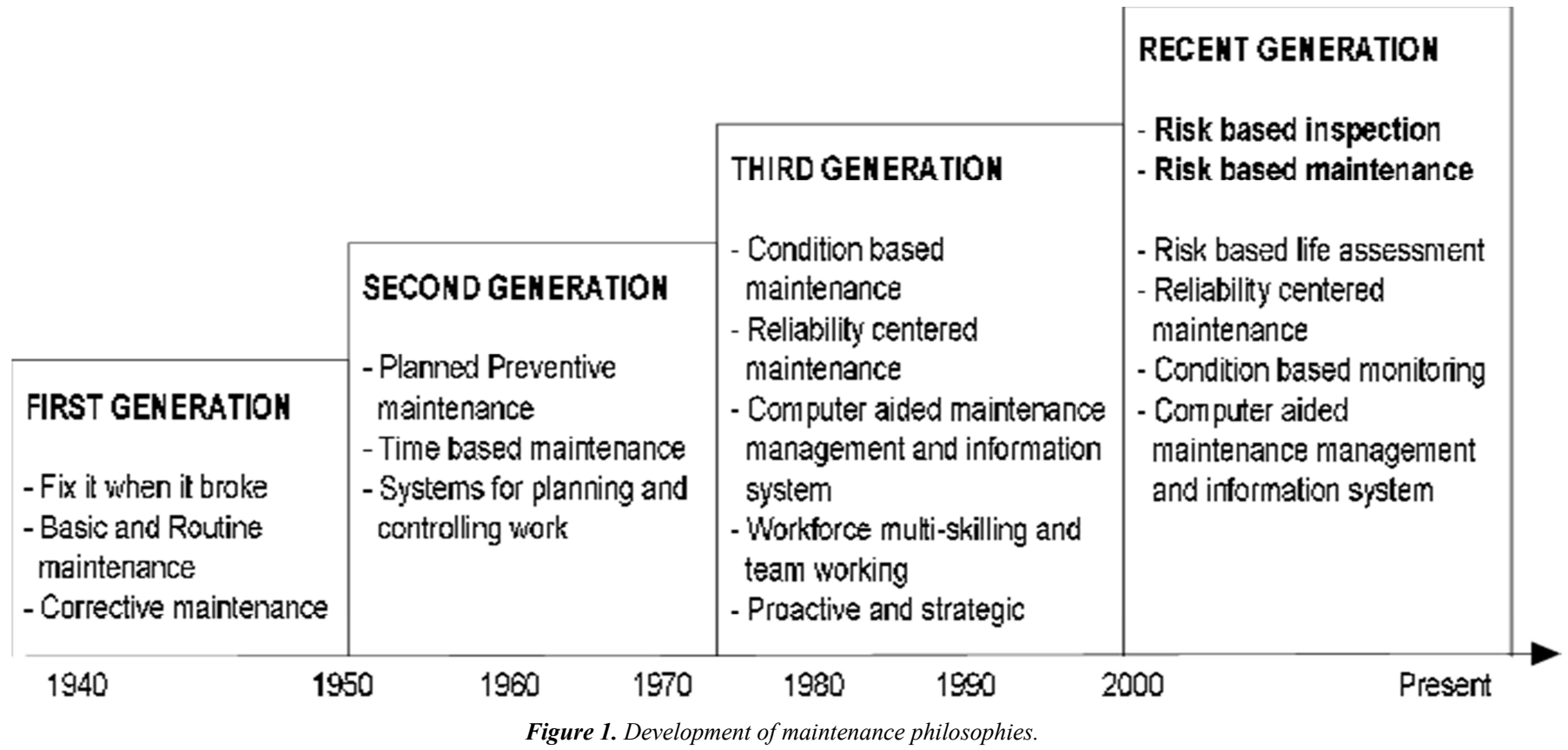

The maintenance policies could not predict failures and the industries would perform maintenance after the machines broke down [16].

In the second generation, Industries become more automated and high reliance of machine in the manufacturing of products was experienced. The maintenance techniques which was adopted in this era included time based maintenance, the system for planning and controlling work, planned preventive maintenance. This is preplanned, preprogrammed, run based schedule maintenance policy for medical equipment and related plants.

In Kenya, biomedical technologist have increasingly adopted this mode of maintenance to handle failed critical medical equipment despite portraying several challenges in the industry. The planned preventive maintenance performs unnecessary maintenance regardless of the actual condition of the equipment thus increase the cost of operation. There is a potential error of replacement of sound medical device or damage of same due to repeated and unneeded maintenance [17]. Preventive maintenance is demanding activity, mostly when applied across numerous medical equipment in the hospital and therefore ineffective maintenance will lead to catastrophic component failures.

The recommendation on (PM) intervals which may be guided by regulating authorities and accreditation organization or manufacturing companies have been an obstacle to the implementation of maintenance policies in the industries [18]. Therefore evaluation of maintenance performance based on safety performance inspection (SPI), periodic replacement of parts or calibrations and schedule or time maintenance would not be possible [19].

The manufacturing industries have pointed out that traditional Preventive maintenance (PM) is often unnecessary, if not counterproductive. However, biomedical engineers are yet to implement maintenance policies which entails analyzing the outcome of maintenance rather than process 
measures which are commonly being practiced in the hospital set up [20].

This uncertainty caused by the planned preventive maintenance may result to medical equipment downtime period being longer, the increase of maintenance cost, disruption of normal operations and uncertainty on the availability of medical equipment when required and also poor patient service outcome effects. The third generation is typically characterized by accelerating the use of automation, equipment becoming a micro-electromechanical system and leaning more to information technology in their applications. During this generation several maintenance policies were implemented which included; reliability centered maintenance (RCM), Condition based maintenance (CBM), and computer aided maintenance management. James Herbert [21] observed that RCM was an improvement of planned preventive maintenance policy as it eliminates unnecessary maintenance and costs. The maintenance policy would be an ideal maintenance technique for the hospital environment as it replaces preventive maintenance programme which could not prevent all failures. The reliability centered maintenance (RCM) would implement an effective form of scheduled maintenance to handle medical equipment in the inventory. RCM is an empirical approach based on the study of operating need, causes of failure and condition monitoring of the system. It identifies the weakest or most critical component with the highest probability of failure for the system or equipment to collapse and initiates stringent maintenance programs for the components [12]. The maintenance process currently being implemented in the industries must optimize the total life cycle cost of operation, improve the safety of the workers and reduce environmental pollution so as to increase the profit margin in the company. The recent generation began in 2000 to the present date. The main focus of the current maintenance policy has been highly characterized by the integration of maintenance technique and the safety policy in the industry. The typical types of this maintenance technique included and not limited to risk-based inspection and risk-based maintenance in addition to RCM and CBM [16].

\section{Optimization of Maintenance Strategy for Critical Medical Equipment}

The key objective of the maintenance processes is to improve the reliability, safety and manufacturers set specification and clinical requirement in medical equipment. Maintenance is considered as unnecessary practice by the facility managers as it delays or obstructs the health service delivery. However, maintenance strategy is the pivot point for the success of health delivery services by the medical equipment in the hospitals. There is a need for an amalgamation of maintenance and other production processes in the industry to increase the profit and reduce the total cost [22]. Tremendous and competitive health service delivery depends on reliable, availability and productivity of state of art medical equipment.

Maintenance strategies have evolved from simple maintenance technology to most complicate policies. Organizations are faced with challenges on choosing the most efficient and effective strategies to enhance the operational capabilities continually, to reduce the maintenance costs and to achieve competitiveness in the industry in question. The efficiency and effectiveness of maintenance policies and strategies for asset maintenance are paramount to the industries in order to achieve the set goals [23].

A good strategy of maintenance is very much needed, which helps to improve and maintain the productivity, quality and most importantly the operational cost. Maintenance has be-come one of the most expedient approaches to guarantee high machine dependability [24].

Hemodialysis machines with a high maintenance standard are able to deliver proper settings to the patient with less or no failures. Dialysis quality is a complex and evolutionary concept that has to be viewed in a quality assurance process to improve outcomes of end stage renal disease (ESRD) patients. To simplify this assessment it is very important that dialysis machines have to be maintained on a regular basis. The overall goal of the maintenance procedures is to raise the overall equipment effectiveness. Evidence in the literature points that mathematical modeling is much more flexible than empirical approaches, and medical maintenance would benefit from optimization modeling [25]. Khalaf et al. [26, 27] proposed a mathematical model that adopted a mixed integer based approach maintenance scheduling technique a software maintainability for maintenance predication purposes was formulated based on both experience in software architecture development and haemodialysis machine architecture. The key performance indicators for the software design included maintainability, re-usability, safety, real-timeliness and demonstrability [28]. Proper identification and selection of an effective and efficient maintenance strategy is an important factor in the maintenance process. Selecting the most efficient maintenance policy is a significant issue that an industry has to deal with to achieve product quality, improved efficiency, safety, productivity and customer satisfaction [29].

Reliability centered maintenance (RCM) utilizes the systematic approach of maintenance planning applied on selecting the suitable maintenance action [30]. Additionally, [31] there is the method of multiple criteria decision making (MCDM), which is implemented in some cases. Different methods have different strengths and weaknesses, for instance block and age models only deal with preventive maintenance and require historical failure data; the RCM procedure does not consider the organizational aspects;

MCDM-method does not consider technical analysis before data gathering.

Bevilaqua and Braglia [32, 33] proposed use of Analytic Hierarchy Process (AHP) as a tool for a decision making method in selecting the best maintenance strategy in which multiple criteria were considered for prioritizing alternatives 
in newly proposed integrated gasification and combined cycle plant in an Italian oil refinery industry. Five maintenance strategies were considered: preventive, predictive, condition-based, corrective and opportunistic maintenance. The objective was to select the best maintenance policy for each facility of the plant in which they were approximately 200 in total. The machines were clustered in three homogeneous groups after a criticality analysis based on internal procedures of the oil refinery.

Ratnayake et al. [34] have also developed AHP method to determine the optimal maintenance policy considering health, safety, environment and finance factors for oil and gas industry. Ali Azadeh et al. [29] stated that a process of selecting appropriate maintenance strategy is a complex multiple-criteria decision-making (MCDM) problem. The authors proposed a fuzzy analytic hierarchy process (FAHP) fuzzy MCDM approach in an attempt to make a comparison between four well-known maintenance policies, deal with the problem of ranking different maintenance policies. Four commonly per-formed maintenance strategies, namely condition based, time-based, failure-based and opportunistic were considered as alternatives, and a real-world case study as a typical MCDM problem was addressed through the proposed approach.

Wang et al. [35] attempted to evaluate different maintenance strategies comprising CM, PM, CBM and TBM for different equipment, and used a FAHP, as an evaluation instrument, to address the imprecise and uncertain judgment

\section{of decision makers.}

Houria et al. [33] proposed a fuzzy Multiple Criteria Decision Making (MCDM) methodology to calculate first the criticality of each medical device and classify the maintenance strategies based on several criteria, and then select the most appropriate maintenance strategy. The methodology was based on Fuzzy Analytical Hierarchy Approach (FAHP) coupled with fuzzy Technique for Order Preference by Similarity to Ideal Situation (TOPSIS). To improve on the selection of appropriate maintenance strategy to medical equipment, the future work was proposed to focus on the development of a Mixed Integer Linear Programming.

Houria et al. [36] proposed further an integrated approach that includes several tools from the literature, namely, the Analytical Hierarchy Process (AHP), the Technique for Order Preference by Similarity to Ideal Solution (TOPSIS), and the mathematical optimization (especially mixed integer problems MILP) to provide the decision maker of the maintenance department with an entire solution to the problem at hand. These three tools were introduced to;

(i) determine the criticality of medical equipment based on a multi-criteria analysis, (ii) rank the different maintenance strategies based on their (benefits) importance to the hospital and (iii) select the optimal maintenance strategy for each device while keeping the total maintenance costs within a predetermined budget.

Table 1 shows a summary of literature review on optimization of maintenance strategy

Table 1. Optimization of maintenance strategy.

\begin{tabular}{|c|c|c|c|c|}
\hline Paper & Summary & Policies & Objective & Methodology \\
\hline Ilangkumaran and Kumanan & $\begin{array}{l}\text { Focused on selecting an } \\
\text { optimum maintenance strategy }\end{array}$ & $\mathrm{PM}, \mathrm{CBM}, \mathrm{PRM}$ and $\mathrm{RCM}$ & Comparison and ranking & AHP and TOPSIS \\
\hline \multirow[b]{2}{*}{ Arunraj and Maiti } & for a textile industry & & & \\
\hline & $\begin{array}{l}\text { Presented an approach based on } \\
\text { risk of equipment failure and }\end{array}$ & CM, CBM, TBM and SM & Comparison and ranking & $\begin{array}{l}\text { AHP and goal } \\
\text { programming }\end{array}$ \\
\hline \multirow{3}{*}{ Bashiri et al. } & cost of maintenance & & & \\
\hline & Presented a new approach for & $\begin{array}{l}\text { CM, PM, CBM, TBM and } \\
\text { PRM }\end{array}$ & Comparison and ranking & $\begin{array}{l}\text { Interactive fuzzy linear } \\
\text { assignment }\end{array}$ \\
\hline & selecting optimum maintenance & & & method (IFLAM) \\
\hline \multirow{2}{*}{ Wang et al. } & $\begin{array}{l}\text { strategy using qualitative and } \\
\text { quantitative data }\end{array}$ & & & \\
\hline & Evaluated different maintenance & CM, TBM, CBM and PRM & Comparison and ranking & FAHP \\
\hline \multirow[t]{2}{*}{ Zaim et al. } & $\begin{array}{l}\text { policies for different equipment } \\
\text { Showed the applicability of two } \\
\text { decision-making techniques in }\end{array}$ & CM, TBM and PRM & Comparison and ranking & AHP and ANP \\
\hline & selecting the most appropriate & & & \\
\hline Koochaki et al. & $\begin{array}{l}\text { maintenance strategy } \\
\text { Studied maintenance policies on } \\
\text { a plant-wide level }\end{array}$ & $\mathrm{CBM}, \mathrm{ABM}$ and $\mathrm{BR}$ & Comparison and ranking & Simulation \\
\hline \multirow[t]{3}{*}{ Ali Azadeh et al. } & Performs a comprehensive & $\begin{array}{l}\text { CBM, TBM, FBM and } \\
\text { OM }\end{array}$ & Comparison and ranking & $\begin{array}{l}\text { FAHP-distance-based } \\
\text { fuzzy MCDM approach }\end{array}$ \\
\hline & comparison between different & & & \\
\hline & maintenance policies & & & \\
\hline
\end{tabular}

PRM: predictive maintenance; RCM: reliability centered maintenance; SM: shutdown maintenance; BR: block replacement; PM: preventive maintenance; CBM: condition-based maintenance; TBM: time-based maintenance; ABM: age-based maintenance; FBM: failure-based maintenance; OM: opportunistic maintenance; AHP: analytic hierarchy process; TOPSIS: technique for the order of prioritization by Similarity to ideal solution; FAHP: fuzzy analytic hierarchy process; ANP: analytic network process; MCDM: multiple-criteria decision-making. 
Siew-Hong et al. [37] proposed method based on the integration of fuzzy TOPSIS for determining the optimal maintenance policy in manufacturing industries. Fouladgar et al. [38] introduced a new fuzzy MCDM technique based on the concepts of COPRAS (Complex Proportional Assessment) and FAHP to assess the feasible maintenance policy, in which linguistic statements were applied to determine the ratings and weights, using a fuzzy MCDM evaluation methodology.

Al-Najjar and Alsyouf [39] evaluated the most popular maintenance policies to select the most appropriate one.

Castro et al. [40] studied an age-based PM and aimed at determining an optimal planned replacement time $(\mathrm{T})$ for critical systems or structures that are exposed to a gradual degradation phenomenon, such as stress corrosion cracking, with the purpose of minimizing the expected cost rate of the system.

Huynh et al. [41] studied different maintenance policies to make a minimal repair decision for single-unit repairable systems.

Marseguerra et al. [42] focused on a continuously monitored multi-component system and, using the genetic algorithm (GA), attempted to identify the optimal degradation level beyond which PM must be performed.

Bashiri et al. [43] proposed a qualitative and quantitative technique on optimization of maintenance strategy. An interactive fuzzy linear assignment method was incorporated to rank the maintenance strategies. However, human judgment being subjected to a certain level of uncertainty due to the different experience the method had several challenges.

Jafari et al. [44] presented a new methodology that used the fuzzy Delphi technique in Simple Additive Weighting (SAW) for the maintenance strategy selection problem (MSSP).

Tiwari et al. [45] proposed an application of ACO to solve real-world problems by resolving the complex process plan selection (PPS) problem. The primary advantage of using ACO is that it stabilizes the solution with considerably less computational effort and time without any deterioration in the quality.

Mafoud [25] addressed a better part of existing publications on preventive maintenance optimization, particularly applied and validated models in healthcare domain. The study reviewed various important aspects of medical equipment maintenance, analyzes different research insufficiency found in healthcare maintenance optimization modelling literature, and proposed directions to develop suitable tools for better medical devices management. However, [12] pointed out that the application of maintenance optimization models to medical devices is rather scarce and new.

The medical equipment maintenance cost determined the decision for acquiring new equipment. System dynamics has several applications and uses such as: hemodialysis performance control [46, 24, 47], and hospital waste management [48].

\section{Conclusion}

The review on strategic maintenance practices provides a platform for researchers in biomedical engineering field, an opportunity to develop a more sophisticated systems to handle challenges in the maintenance management.

The method used for optimization of strategic maintenance policy ought to be less expert reliant to avoid uncertainty and ambiguity in decision making. The ant colony optimization (ACO) algorithms is the best technique for selection of maintenance process in the healthcare. It is multi-agent systems in which it mimics the behavior of ant colony in decision making. A predictive and intelligent management system customized for in-house decision making computerized maintenance management systems may provide the best maintenance management of hemodialysis medical equipment in the healthcare. This might be guided by key performance indicators to optimize on the best maintenance process.

The reliability of the hemodialysis shall be improved while providing services in the hospital. The system shall reduce the Mean Downtime (MDT) and Mean time to repair (MTTR) for a failed medical equipment.

\section{References}

[1] Jan Sternby, "Adaptive Control of Ultrafiltration," IEEE Transactions on Control Systems Technology, vol. Vol. 4, pp. pp 11-17, 1996.

[2] Madhukar MISRA, "The basics of hemodialysis equipment," Hemodialysis International, vol. 9, pp 30-36, 2005.

[3] Jzsef Klespitz, Levente Kovcs, "Peristaltic pumps a review on working and control possibilities," in SAMI 2014 IEEE 12th International Symposium on Applied Machine Intelligence and Informatics Herlany, Slovakia, January 23-25, 2014.

[4] K. R. Peter Rhys Lewis and C. Gagg, Forensic Materials Engineering: case studies. CRC Press LLC, 2004.

[5] Ahmad Taher Azar, "The influence of maintenance quality of hemodialysis machines on Hemodialysis efficiency." Saudi Journal of Kidney Diseases and Transplantation, vol. vol. 20(1), pp 49-56, 2009.

[6] Jzsef Klespitz, Levente Kovcs, "Identification and control of peristaltic pumps in hemodialysis machines," in CINTI 2013 14th IEEE International Symposium on Computational Intelligence and Informatics 1921 November, 2013 Budapest, Hungary, 1921 November, 2013.

[7] Jzsef Klespitz, Mrta Takcs, Imre Rudas and Levente Kovcs, "Adaptive soft computing methods for control of hemodialysis machine," in Proceedings of fuzzy 2014, Kaohsiung, Taiwan, Nov. 26-28, 2014, Nov. 26-28, 2014.

[8] Isaiah Lucheli, "Kidney patientssue State over lack of dialysis machines," tech. rep., Standard Media, https://www.standardmedia.co.ke/article/2000082436/kidneypatients-sue-state-over-lack-of-dialysis-machines, April 2013. 
[9] Khalaf AB., "Maintenance model for minimizing risk and optimizing cost effectiveness of medical equipment in Palestine." Journal of Clinical Engineering, vol. 14, pp. 36493653,2004

[10] Sawsan Mekki, Manal Abdel Wahed, Khaled K. Wahba, Bassem K. Ouda, "A System Dynamics Based Model for Medical Equipment Maintenance Procedure Planning in Developing Countries," in Cairo International Biomedical Engineering Conference (CIBEC) Cairo, Egypt, 2012.

[11] Malek Masmoudi, Zeineb Ben Houria, Ahmad Al Hanbali, and Faouzi Masmoudi, "Decision Support Procedure for Medical Equipment Maintenance Management," Journal of Clinical Engineering, vol. Volume 41, pp. 19-29, January/March 2016.

[12] Afshin Jamshidi, Samira Abbasgholizadeh Rahimi, Daoud Ait-kadi, "Medical devices Inspection and Maintenance; A Literature Review," in Proceedings of the Industrial and Systems Engineering Research Conference Y. Guan and H. Liao, eds., 2014.

[13] Keil, O. R., "Unnecessary Preventative Maintenance: Its Effect on Opportunity Costs," Journal of Clinical Engineering 33(1): 8, vol. (33)1, p. 8, 2008.

[14] Ali M. Abdo, Manal Abdel Wahed, Amr Sharawi, "Dynamic Model for Evaluation of Medical Devices Maintenance in Developing Countries," International Journal of Application or Innovation in Engineering \& Management (IJAIEM), vol. 3, pp. ISSN $2319-4847,2014$.

[15] Cynthia Olotch, "Managed Equipment Services (MES) Healthcare for Sustainable Development: The Kenya MES experience," tech. rep., 2018.

[16] N. S. Arunraj, J. Maiti,, "Risk-based maintenance Techniques and applications," Journal of Hazardous Materials, vol. 142, pp. 653-661, 2007.

[17] M. C. ETI, S. O. T. Ogaji, S. D. Probert, "Development and implementation of preventive-maintenance practices in Nigerian industries," Applied Energy, vol. 83, pp. 1163-1179, 2006.

[18] Ridgway. M, "Manufacturer-recommendation PM intervals: is it time for a change," Biomedical Instrumentation \& Technology, vol. 43, pp. 498-500, 2009.

[19] Wang B and Levenson A, “ Equipment inclusion criteria a new interpretation of JCAHOs medical equipment management standard." J Clin Eng 25(1): 2635, vol. 25(1), pp. 26-35, 2000.

[20] Wang, B., A Practicum for Biomedical Engineering and Technology Management Issue. Kendall Hunt Publishing, 2008.

[21] James Herbert, "Optimization of Clinical Engineering in Private Health-care," in 20th Congress of the International Federation of Hospital Engineering Barcelona, 19 to 22 October 2008.

[22] G. Ettaye, A. El Barkany and A. El Khalfi, "A review of integrated production and preventive maintenance planning models for multi-state systems," IEEE Transactions on Reliability, vol. 59(3), pp. 496-506, 2010.

[23] Uday Kumar, Diego Galar, Aditya Parida and Christer Stenstro, "Maintenance performance metrics: a state-of-the-art review," Journal of Quality in Maintenance Engineering, vol.
19, pp. 233-277, 2013.

[24] Ahmad Azar, Khaled Wahba, Abdalla Mohamed, "System Dynamics Highlights the Effect of Maintenance on Hemodialysis Performance," in 25 International Conference of the System Dynamics Society 2007, pp. 242-261, 2007.

[25] H. Mahfoud, A. El Barkany, and A. El Biyaali, "Preventive Maintenance Optimization in Healthcare omain: Status of Research and Perspective," Journal of Quality and Reliability Engineering, vol. 2016, pp. 1- 10, June 2016.

[26] A. B Khalaf, K. Djouani, Y. Hamam, and Y. Alayli, "Evidence-based mathematical maintenance model for medical equipment," in International Conference on Electronic Devices, systems and applications, 2010.

[27] A. B Khalaf, "Maintenance model for minimizing risk and optimizing cost-effectiveness of medical equipment in Palestine.” Journal Clinical Engineering., vol. 14, 2004.

[28] PerOlof Bengtsson \& Jan Bosch, "Architecture Level Prediction of Soft-ware Maintenance," in In Proceedings of Third European Conference on Software Maintenance and ReEngineering, Amsterdam, Netherlands, pp 139-147, March 1999.

[29] Ali Azadeh and Saeed Abdolhossein Zadeh, "An integrated fuzzy analytic hierarchy process and Fuzzy multiple-criteria decision-making simulation approach for maintenance policy selection," Transactions of the Society for Modeling and Simulation International, vol. 92(1), pp. 3- 18, 2016.

[30] O' Connor, Patrick D. T, Practical Reliability Engineering. Wiley Chichester, 4 ed., 2002.

[31] Alsyouf, Imad, Cost Effective Maintenance for competitive Advantages No. 33, Intellectual Docusys, Goteborg, Sweden, 2004.

[32] Bevilacqua, M. and Braglia, M., "The analytic hierarchy process applied to maintenance strategy selection 70 (1), pp 71-83.," Reliability Engineering and System Safety, vol. 70(1), pp. 71-83, 2000.

[33] Zeineb Ben Houria, M. Besbes, B. Elaoud, M. Masmoudi and Faouzi Masmoudi, "Maintenance strategy selection for medical equipment using fuzzy multiple criteria decision making approach," in CIE45 Proceedings, 28-30 October 2015.

[34] R. C. Ratnayake and T. Markeset, "Methodology and theory: Technical integrity management: Measuring HSE awareness using AHP in selecting a maintenance strategy," Journal of Quality in Maintenance Engineering, vol. 16(1), pp. 44-63, 2010.

[35] Wang L, Chu J and Wu J., "Selection of optimum maintenance strategies based on a fuzzy analytic hierarchy process." International Journal of Production Economics, vol. 107, pp. 151-163, 2007.

[36] Zeineb Ben Houria, Malek Masmoudi, Ahmad Al Hanbali, Ikram Khatrouch and Faouzi Masmoudi,"Quantitative techniques for medical equipment maintenance management," European Journal of Industrial Engineering, vol. x, no. x, xxxx, January 2017.

[37] Siew-Hong, Ding and Shahrul Kamaruddin, "Selection of Optimal Maintenance Policy by Using Fuzzy Multi Criteria Decision Making Method," in Proceedings of the 2012 International Conference on Industrial Engineering and Operations Management Istanbul, Turkey, July 362012. 
[38] Fouladgar MM, Yazdani-Chamzini A, Lashgari A, et al., "Maintenance strategy selection using AHP and COPRAS under fuzzy environment." International Journal of Strategic Property Management, vol. 16, pp. 85-104, 2012.

[39] Al-Najjar B and Alsyouf I., "Selecting the most efficient maintenance approach using Fuzzy Multiple Criteria Decision Making," International Journal of Production Economics, vol. 84, pp. 85-100, 2003.

[40] Castro IT, Barros A and Grall A. , " Age-based preventive maintenance for passive components submitted to stress corrosion cracking." Mathematical and Computer Modelling, vol. 54, p. 598-609, 2011.

[41] Huynh KT, Castro IT, Barros A, et al., "Modeling age-based maintenance strategies with minimal repairs for systems subject to competing failure modes due to degradation and shocks.” European Journal of Operational Research, vol. 218, pp. 140-151, 2012.

[42] Marseguerra M, Zio E and Podofillini L., " Condition-based maintenance optimization by means of Genetic Algorithms and Monte Carlo Simulation. ," Reliability Engineering \& System Safety, vol. 77, pp. 151-165, 2002.

[43] Bashiri M, Badri H and Hejazi TH., "Selecting optimum maintenance strategy by Fuzzy Interactive Linear Assignment method." Applied Mathematical Modelling, vol. 35, pp. 152164, 2011.
[44] Jafari A, Jafarian M, Zareei A, et al. , "Using fuzzy Delphi method in maintenance strategy selection problem.," Journal of uncertain systems, vol. 2, pp. 289-298, 2008.

[45] M K Tiwari, Y Dashora, S Kumar and R Shankar, "Ant colony optimization to select the best rocess plan in an automated manufacturing environment," Journal of Engineering Manufacture, vol. 220, pp. 1457-1472, 2006.

[46] Ahmad Taher Azar, and Khaled M. Wahba, "Biofeedback Control of Ultrafiltration for Prevention of Hemodialysis Induced Hypotension," in Proceedings of the 26th International Conference of the System Dynamics Society, Athens, Greece, July 20 24, 2008.

[47] Ahmad Taher Azar, and D. Khaled M. Wahba., "Association between Neural Network and System Dynamics to Predict Dialysis Dose during Hemodialysis." in Proceedings of the 26th International Conference of the System Dynamics Society, Athens, Greece, July 20 24, 2008.

[48] Mochammad Chaerul, Masaru Tanaka, Ashok V. Shekdar, "A system dy-namics approach for hospital waste management." Waste Management, vol. 28, pp. 442-449, 2008. 